\title{
The Development of Remote Labor Training System for Rural Small Towns Based on MVC Model
}

\author{
Lihua Zheng, Dongmei Zhao*, Nan Zhou, Xiaobing Qiu, Li Xu, \\ Shicong Wang, and Zhong Qiao \\ The College of Information and Electrical Engineering, \\ China Agricultural University, Beijing 100083, China \\ zhaodongm@vip.163.com
}

\begin{abstract}
In view of the characteristics of the rural labor force in China, a remote training system for small towns is developed based on B/S architecture and MVC model by using object-oriented and JSP technology on the Java J2EE platform. The system is designed to be used by administrator, training enterprise and individuals. The administrator can manage the website, permission assignment and maintain database. Training enterprise can use the system as their working operation platform. They can release their business information, manage their training materials and maintain their own data in the database. A registered individual user can access the information within his respective authorities, take study online, take part in the test online, question online, etc. By means of UML, the system is analyzed and both the database and class structure are built. By using Filter, Struts and Hibernate technologies, the system is developed with the characteristics of crossing-platform, better expansibility and maintainability.
\end{abstract}

Keywords: Remote rural labor training system, MVC, JSP, B/S, UML.

\section{Introduction}

With China economic and cultural development, 3-issues concerning Chinese agriculture, rural areas and farmers are increasingly becoming the critical factors which restrict the development of overall national strength. It is the key to solve the issue of farmers by reasonable transferring the rural surplus labors to urban. An investigation showed that china mobile population had reached 21.1 billion in 2009, the average age at about 27.3 and $78.7 \%$ of them come from rural and they mainly engaged in low wages or dangerous industries [1]. This condition made serious challenge to national strategic planning, social management and public services, and in the meantime, it is becoming a social instability problem. Hence it is the essence way to address the problem of migrant workers' employment by increasing their professional skills, enhancing their operational qualities and improving their knowledge structure and quality.

\footnotetext{
* Corresponding author.
} 
Y. J. He et al [2], W. C. Qin [3], W. L. Wang et al [4], Z. H. Tian [5] and W. Huang [6] analyzed the forming reasons and status quo of china rural labor resources quality, and brought forward many constructive views. Since the rural labor force in China has a number of large, strong mobility and relatively unenlightened knowledge structure, D. R. Zhong et al [7], Z. H. Han et al [8], D. X. Fu [9], X. Liu et al [10], Z. H. Han et al [11], S. Y. Wang et al [12], A. H. Xi et al [13] and J. X. Guan [14] have taken great effort to do large-scale research and in-depth investigation. Then they drew the same conclusion that it is the only right way to solve the problem of farmers by taking a road of orderly and stable training transfer.

However, it is impossible to organize the farmers to learn together because they are scattering in various places and various fields. C. H. Pan et al [15], Y. C. Wu et al [16], Y. Chen et al [17], H. W. Luo et al [18], X. J. Huang et al [19] made out a solution for the vocational education status quo, that is, remote training by means of internet platform.

With the spread of the computer and internet, it is becoming possible to delivery tele-educational materials through internet. A practical remote training platform for both training organizations and rural surplus labors should be very much helpful and widely needed. It can help the training organizations mapping out their training plan according to the labor force supply and market demand, and changing timely. And on the other hand, it can help the rural surplus labors finding a right and convenient way to learn knowledge and skills and lead them to apply a suitable urban job. And on a long view, it might help the government to adjust the industry positioning, to transfer rural surplus labor force reasonably and orderly, to maintain social stability and healthy development, so as to solve the facing three rural issues finally.

\section{System Design}

In response to the knowledge level and features of the rural surplus labor force, the remote labor training system was designed as B/S structure, and developed on J2EE platform by using object-oriented technology based on MVC model. The software developing environment included IE6.0, Tomcat 6, JDK 1.4.2, SQL Server 2000, Eclipse Galileo with struts 2 and hibernate.

\subsection{System Function Analysis}

The system was designed as multi-user system, which included system administrator, enterprise user, personal user and its son-class of register personal user. Fig. 1 shows the use case diagram of the system.

For administrator, the completed background management function was provided by the system. It comprised user management, item bank management, materials management, common training information management, common data maintenance, etc.

For enterprise user, a multi-user platform was built by the system. The registered training company could achieve its training business management by means of this platform, which consisted of training and interview information releasing, new trainees enrolling, training materials delivering and its maintaining, item bank maintaining and online training. 


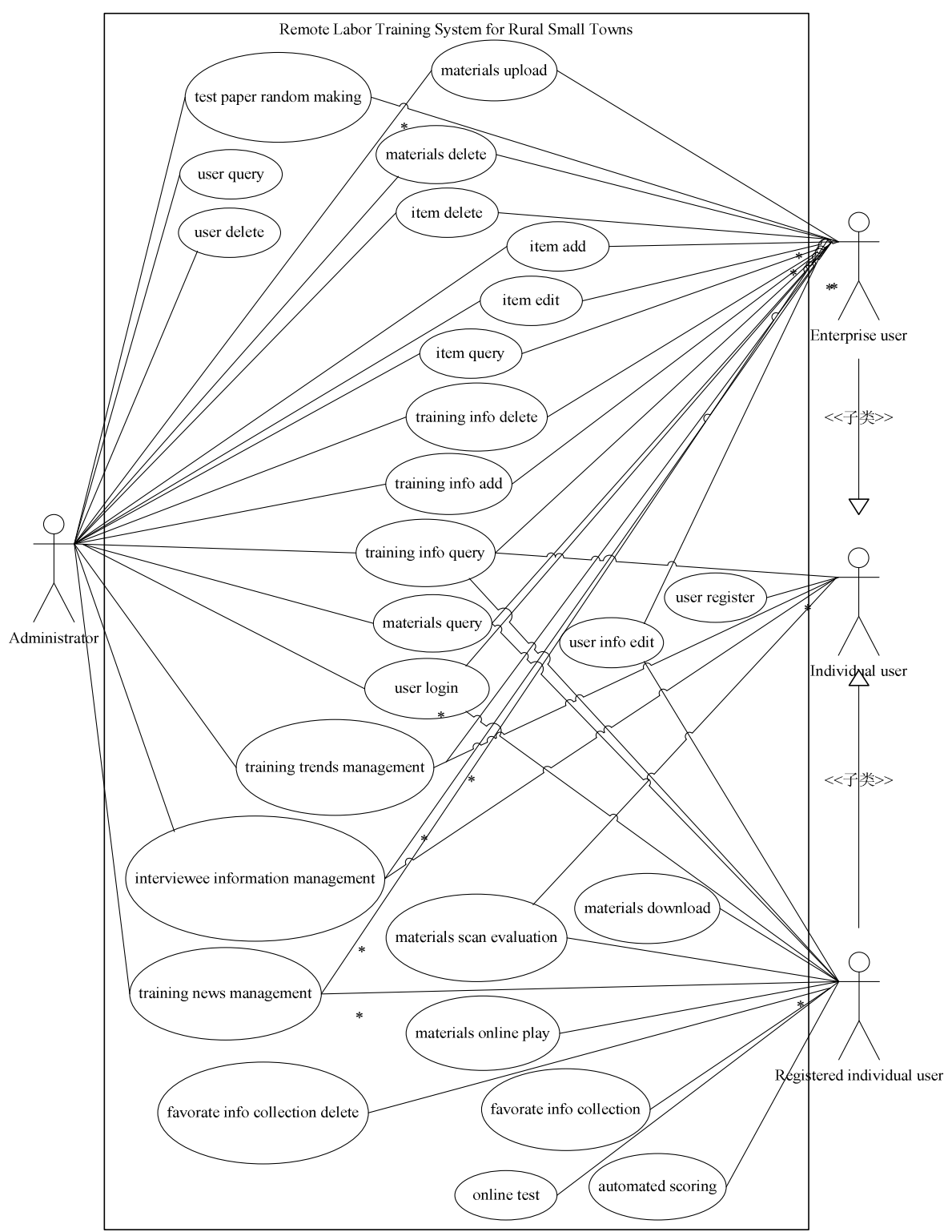

Fig. 1. Use case diagram of the remote labor training system for rural small town

For registered individual user, a plenty of powerful and convenient functions were provided by the system. If the individual user chose a training institution to register as its trainee, the services of that company would become available to him. Trainees could choose a suitable training project for his professional study. Then he could 
inquiry the relevant information, download training materials, join in the online training, question and get answers online, take online test, submit the examination paper and retrieve the answer sheet and check the test point and item analysis. On addition, trainees could collect the favorite information to their bench which provided by the system, advertise his job application form, etc.

And an ordinary user was allowed to browse the common information of the site.

\subsection{System Module Design}

According to the function analysis of the system, ten modules as well as their submodules contained by the system were drawn out. The whole module structure of the system is shown as Fig. 2.

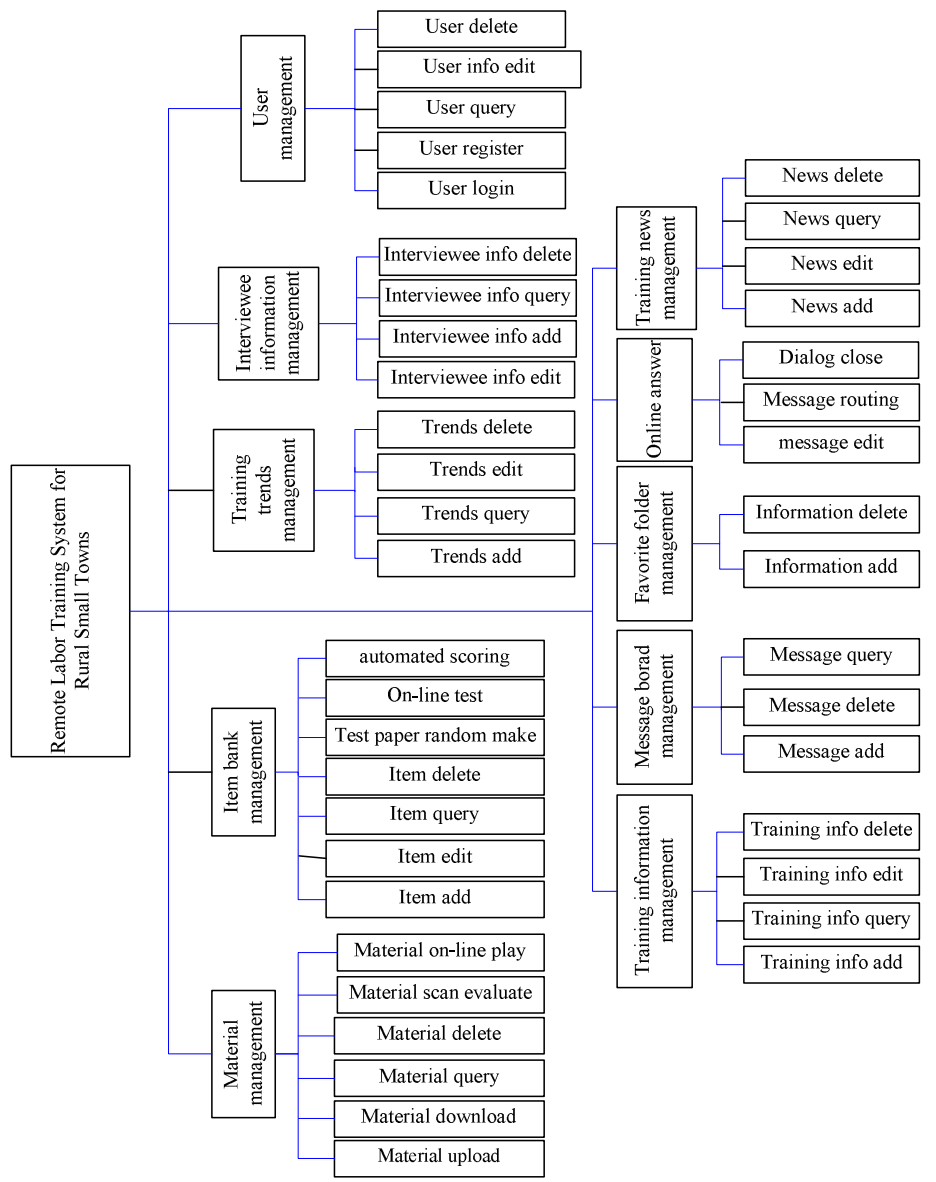

Fig. 2. The module structure diagram of the remote labor training system for rural small town 
They were user management, material management, item bank management, favorite folder management, online answer management, training news management, interview information management, training trends management, training information management and message board management. Each module included its sub modules, such as, the module of material management comprised material upload, material download, material query, material delete, material scan evaluate and material online play.

Various sub modules were developed tally with high cohesion and would be called by the relevant invoker with their corresponding rights. For the above example module, the sub-modules of material upload and material delete were assigned for the administrator and registered enterprise user. Thereinto the administrator could upload and delete the common materials, and the registered enterprise user could upload and delete his own training materials; The sub-module of material download was assigned for the registered individual user, who could download the common materials from administrator as well as the materials from the belonged training institution; The submodule of material query was designed for all of users but with different query conditions respectively, i.e. the administrator could retrieve the materials uploaded by himself and any other enterprise users, the registered enterprise user could only access the materials uploaded by itself, and the registered individual user could only query the common materials or the materials from the training company which he belonged to; The sub modules of the material scan evaluate and material online play were assigned for the registered individual user who could release his comments about the materials; And at the mean time, the materials such as *.doc, *.xls, *.ppt, *.swf, *.avi, *.wmv, *.mpg, etc. could be played or opened online.

\subsection{System Database Design}

To a B/S web application system, designing and building a correct and proper database is the key to success. Bolstered by the powerful functions of MS SQL Server2000, a relational database which meets the third normal form for the remote labor training system is designed and established based on object-oriented data analyzing.

\subsubsection{Logical Design of the Database}

By investigating the entities and the relationship between them elaborately, the E-R diagram of the system was obtained. And it is shown in Fig. 3.

\subsubsection{Physical Design of the Database}

According to the logical design of the database, fifteen base tables are established in terms of the third normal form. Table 1 shows the main information of all the tables. 


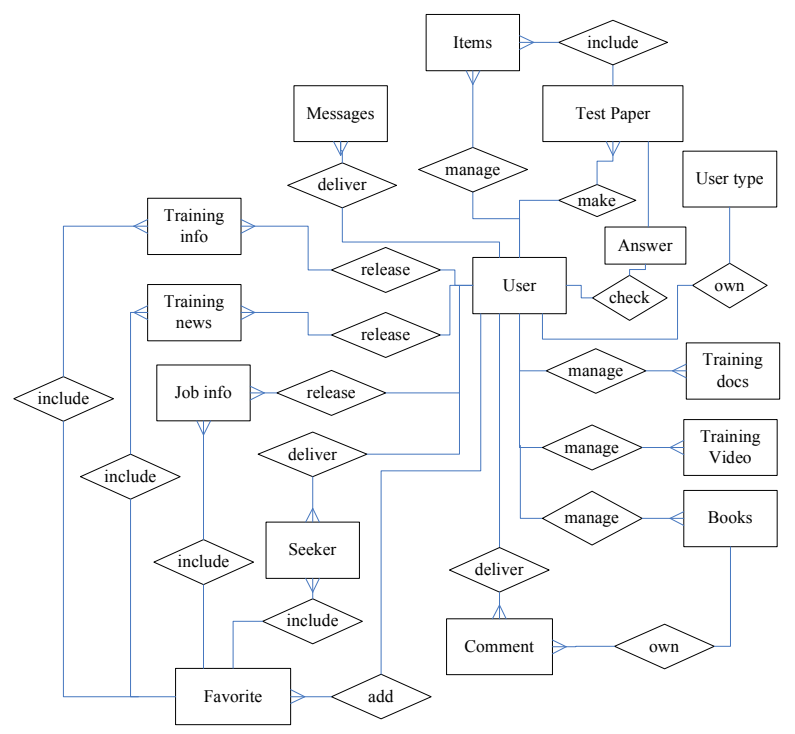

Fig. 3. The E-R diagram of the remote labor training system for rural small town

Table 1. The information of the base tables

\begin{tabular}{llll}
\hline table & Primary key & Foreign key & Field number \\
\hline tb_user & ID/username & Usertype & 12 \\
tb_usertype & ID & & 2 \\
tb_docs & ID & username/usertype & 8 \\
tb_test & ID & username/usertype & 17 \\
tb_comment & ID & Username/usertype/Book_ID & 7 \\
tb_books & Book_ID & Username/usertype & 8 \\
tb_favorite & ID & Username/usertype & 6 \\
tb_news & ID & Username/usertype & 6 \\
tb_leaveword & ID & Username/usertype & 6 \\
tb_traininginfo & ID & Username/usertype & 9 \\
tb_exampaper & ID & Username/usertype & 16 \\
tb_seeker & ID & Username/usertype & 10 \\
tb_video & ID & Username/usertype & 7 \\
tb_job & ID & Username/usertype & 10 \\
\hline
\end{tabular}




\subsection{System Class Design}

According to the E-R diagram and data analysis, seventeen entity classes were built. Fig. 4 shows the classes and their relationship.

By using Struts framework, fourteen action classes were established to acquire the data from forms and transmit them to the business logic layer. And then the JavaBeans were called to fulfill the main performances or to forward HTTP requests to JSPs. In addition, seventeen DAO classes inherited from Hibernate SessionFactory were built to implement the persistent layer; Two classes implementing Filter interface were used to filtrate character set encoding and login request; Three Servlet classes were used to control online questioning and answering; Several other classes were built to implement the common functions or to assist to implement some function.

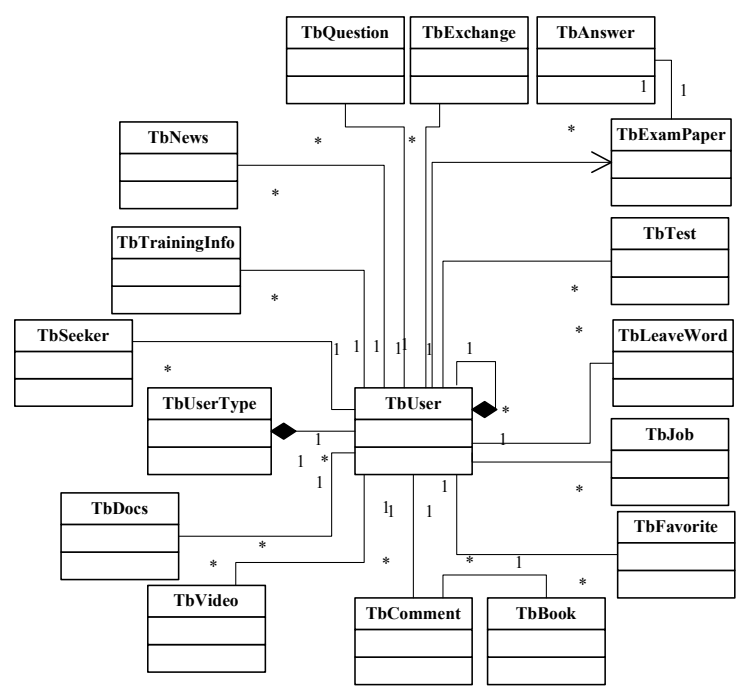

Fig. 4. The class diagram of the remote labor training system for rural small town

\section{System Implementation}

By using Tomcat as the J2EE application server, adopting Struts, Hibernate and Filter as the developing technologies, the data logic layer and business logic layer were established, in which the entity beans were used to implement the system data tier, and action beans were used to implement logical tier. The architecture diagram is shown as Fig. 5. 


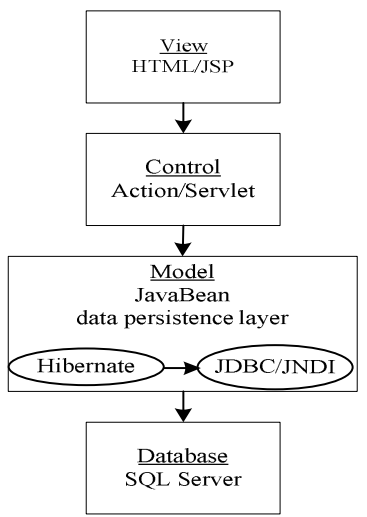

Fig. 5. The architecture based on Hibernate and struts

The remote labor training system mainly consisted of ten modules. Among them, the subscriber management module included user registration, user login/query/delete and user information edition. Question bank management module consisted of add/delete/edit/query question. Training examination management module included random test paper auto-formation, online testing and automatic scoring. Materials management module included upload training materials, query/edit/delete training materials, download general materials, video online play and materials evaluation message. Online Q\&A module was tailor-made for rural training participants, and it consisted of online question, online answer and online exchange. A hundred and seventy five web pages were made in the system. Fig. 6 is the homepage of the registered individual user.

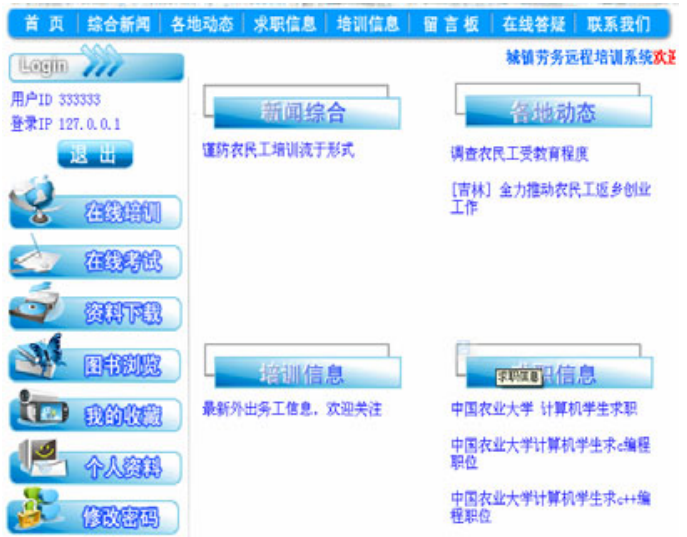

Fig. 6. The homepage of the registered individual user 


\section{Conclusions}

With the step of new socialist countryside building, Chinese government is improving rural communication infrastructure construction gradually. Therefore, remote vocational education is becoming realistic. A suitable and practical teletraining system for small cities and towns can provide convenient service for those rural surplus labors and help them to solve their facing employment problem.

Based on the object-oriented methodology, by means of java developing platform, by using Struts, Filter and Hibernate technologies, the remote labor training system for small rural towns was built with a good man-machine interface, rich applications and easy to operate. It is highly cohesive, loosely coupled, highly credible, easy to maintain and extend.

The system's commissioning showed that it could meet the needs of rural labor remote training service. It is time-saving, low cost, efficient and practical. And it will be helpful for the government to transfer rural surplus labor force to urban cities in an orderly management, so as to untie the facing three rural issues finally.

Acknowledgments. This research was financially supported by the National High Technology Research and Development Program of China (2006BAJ07B02).

\section{References}

1. China mobile population more than 20 Billion, most engage in low wages or dangerous industries, http://news.163.com/10/0627/01/6A584ULD00014AEE.html (in Chinese)

2. He, Y.J., Zhang, J.H.: Discussion on Agricultural Information and Building of the well-off society in an All-round Way in Countryside. Journal of Anhui Agri. Sci. 33(10), 19911993 (2005)

3. Qin, W.C.: The study and reflection of rural labor force transfer in Suining county. China New Technologies and Products 4, 122 (2009) (in Chinese)

4. Wang, W.L., Li, Y.J., Wang, J.D.: The Forming Reasons of China County Remained Labor and Its Transferring Fashion. Journal of Shandong Normal University (Natural Science) 19(2), 62-65 (2004) (in Chinese)

5. Tian, Z.H.: The Thought and Countermeasures of Rural Labor Force Transferring -The Reflection of Todaro Model. Business Economics 11, 24-25 (2006)

6. Huang, W.: Analyzing And Thinking About Employment Difficulty of Shanghai Farmers Leaving Land. Social Watching 12, 5-7 (2005) (in Chinese)

7. Zhong, D.R., Yu, L.Q.: Strengthen The Training of Farmers and Stimulate The Construction of Small Towns. China Adult Education 12, 60 (2000) (in Chinese)

8. Han, Z.H., Qi, Y.J., Qin, L.: The Development of Vocational Education During The Construction of Small Towns. Journal of Heibei Normal University of Science \& Technology (Society Science) 5(3), 18-21 (2006) (in Chinese)

9. Fu, D.X.: The Research of Rural Labor Employment Capacity Training System Building. Special Zone Economy 2, 168-169 (2008) (in Chinese) 
10. Liu, X., Sun, J.Y.: The Training System and Safeguard Mechanism of The Transformation of Rural Labor Force. Vocational And Technical Education 25(16), 59-62 (2004) (in Chinese)

11. Han, Z.H., Sun, J.Y., Yun, X.B., Zhang, G.R., Liu, W.Y.: Discussion on Interaction Between Small Town Construction and Vocational Education Development. Vocational and Technical Education 27(7), 12-14 (2007) (in Chinese)

12. Wang, S.Y., Chen, B.F., Xi, A.H., Zhang, X.L.: The Government Participating in The Vocational Education Development of Small Town. Vocational Education Research 7, 12-13 (2006) (in Chinese)

13. Xi, A.H., Chen, B.F., Qu, X.Q., Ma, Y.: Study on Vocational Education Mode of Wide Places in The Road. Vocational And Technical Education 26(28), 14-16 (2005) (in Chinese)

14. Guan, J.X.: Taking a Road of Development Through Orderly \& Stable Training Transferring. Work Newsletter in Rural Areas 18, 32 (2009) (in Chinese)

15. Pan, C.H., Zhu, T.L., Fu, H.X.: Research on Rural Distance Education And Training System Based on Network. Agriculture Network Information 1, 12-15 (2009) (in Chinese)

16. Wu, Y.C., Zhang, C.L.: Design of Agricultural Science Training System Based on MVC Model. Journal of Agricultural Mechanization Research 5, 246-247 (2004) (in Chinese)

17. Chen, Y., Weng, Q.: By Countryside Science And Technology Information Strut System Constructing. Agriculture Network Information 7, 26-28 (2006) (in Chinese)

18. Luo, H.W., Huang, L., Liu, K., Li, B.T., Yan, X.: Research And Application of The Model of Long-Distance Training of Agriculture sci-tech Based on Internet. Agriculture Network Information 8, 83-86 (2006) (in Chinese)

19. Huang, X.J., Cui, J.X., Luo, H.W., Su, Z.H.: The Explore of Remote Educational Standardization in Guangdong. Guangdong Agricultural Sciences 8, 258-259 (2009) (in Chinese) 